GONÇALVES, C.R.

1961 - O Genero Acromyrmex no Brasil. Studia Entomologica, 4 (1-4): 113-180.

IRMLER, U.

1973 - Population-Dynamic and physiological Adap. tation of Pentacomia egregia Chaud. (Col. Cicindelidae) to the Amazonian Inundation Forest. Amazoniana, 4 (2): 219-227.
LEWIS, T.

1975 - Colony size, density and distribution of the leaf-cutting ant, Acromyrmex octospinosus (Reich) in cultivated fields. Trans. R. Ent. Soc. Lond., 127 (1): 51-64.

SCHALLER, F.

1969 - Zur Frage des Formensehens bei Collembolen. Verh. Dtsch. Zool. Ges. IInnsbruck 1968): $368-375$.

(Aceito para publicação em 18/11/82)

\title{
Comportamento preliminar de duas cultivares de amendoim (Arachis hipogaea L.) uma cultivar americana e outra indígena
}

\author{
Kaoru Yuyama \\ Instituto Nacional de Pesquisas \\ da Amazônia
}

O amendoim (Arachis hipogaea L.) é uma leguminosa com um processo especial de frutificação, denominada geocarpia, em que uma flor aérea, após ser fecundada, produz um fruto subterrâneo. É originária da América do Sul e quando chegaram os primeiros colonizadores lusos no Brasil, verificaram que os índios já plantavam e consumiam (Godoy Passos et al., 1973). Assim sendo, o amendoim adapta-se muito bem ao nosso clima tropical, apesar de a grande maioria das culturas de amendoim no Brasil, localizar-se nos Estados de São Paulo, Paraná e Mato Grosso do Sul com a seguinte participação percentual: $66 \%, 19 \%$ e $9 \%$, respectivamente (CACEX, 1982). A produção média no Brasil é de $1500 \mathrm{~kg} / \mathrm{ha}$, emboro esteja classificada mundialmente como uma das de maior expressão, mas, nos últimos anos, não tem apresentado incremento digno de nota (CACEX, 1982). A maioria das cultivares utilizadas no Brasil são dos grupos "Spanish" e Valência, as quais apresentam a frutificação concentrada na base da planta, facilitando a colheita mecânica.

O Departamento de Ciências Agronômicas do INPA (Instituto Nacional de Pesquisas da Amazônia), através da Divisão de Genética e
Melhoramento, com um programa de coleta, avaliação e melhoramento das espécies nativas e indígenas da Amazônia, conseguiu uma cultivar utilizada pela tribo dos Cinta-Larga da Reserva Indígena de Serra Morena, MT, à qual foi dado o nome de Makap, pois assim é chamado o amendoim na iinguagem indígena. Esta cultivar foi testada com outra americana do grupo Virgínia, chamada "Altika" para comparar e avaliar a adaptação ao meio Amazônico. Foram observados os caracteres de desenvolvimento, produção, adaptabilidade e resistência à pragas e às doenças .

A semeadura foi efetuada no final de novembro, em solo Podzólico, onde havia uma capoeira de três anos recém-desbravada da Colônia Antônio Aleixo no Município de Manaus, AM. Cada parcela constou de quatro linhas de quatro metros de comprimento, com espaçamento de $0,60 \mathrm{~m}$ entre linhas e $0,20 \mathrm{~m}$ entre plantas. Observou-se o comportamento das duas cultviares pela avaliação de doze caracteres, como demonstra a Tabela.

Os dados sobre a altura da planta, diâmetro da planta (comprimento de ramos laterais) e número de vagens por planta foram de valores médios de 10 plantas, sendo que as duas 
TABELA 1 - Principais características avaliadas em dois cultivares de amendoim (Arachis hipogaea L.).

\begin{tabular}{|c|c|c|}
\hline $\begin{array}{c}\text { Cultivares } \\
\text { Característica }\end{array}$ & Makap & Altika \\
\hline Semeadura à emergência (dias) & 6 & 6 \\
\hline Emergência à floração $50 \%$ (dias) & 53 & 43 \\
\hline Emergência à maturação $95 \%$ (dias) & 173 & 150 \\
\hline Altura da planta $(\mathrm{cm})$ & 24,3 & 27,3 \\
\hline Diâmetro da planta $(\mathrm{cm})$ & 86,7 & 82,0 \\
\hline Número de vagens/planta & 24,4 & 44,7 \\
\hline Grupo botânico (1) & Subesp. hipogaea & Subesp. hipogaea \\
\hline Grupo vegetativo (2) & Virgínia & Virginia \\
\hline Desenvolvimento de ramos laterais & Rasteiro & Semi-rasteiro \\
\hline $\begin{array}{l}\text { Produção } \\
\text { de grãos }\end{array} \quad\left\{\begin{array}{l}10 \text { plantas }(\mathrm{g}) \\
\mathrm{kg} / \mathrm{ha}\end{array}\right.$ & $\begin{array}{r}278 \\
1160\end{array}$ & $\begin{array}{r}322 \\
2638\end{array}$ \\
\hline Peso de 100 grãos $(\mathrm{g})$ & 88 & 94 \\
\hline $\begin{array}{l}\text { Ataque de } \\
\text { Doenças }\end{array}\left\{\begin{array}{l}\text { Cercosporiose } \\
\text { Sclerotium } \\
\text { Rhizoctoniose }\end{array}\right.$ & $\begin{array}{l}\text { Resistente } \\
- \\
-\end{array}$ & $\begin{array}{l}\text { Suscetivel } \\
\text { Resistente } \\
\text { Suscetivel }\end{array}$ \\
\hline
\end{tabular}

(1) Krapovickas \& Rigoni, 1950

(2) Gregory et al., 195'

primciras determinações foram efetuadas quando as plantas atingiram o máximo de desenvolvimento, isto é, logo após a floração, e a última depois da colheita. Os dados referentes à produção de grãos foram coletadas apenas de plantas nas linhas centrais.

A classificação do grupo botânico c grupo vegetativo seguiu metodologia de Krapovickas \& Rigoni (1950) e Gregory et al., (1951), respectivamente.

Verificou-se que a cultivar Makap tem crescimento rasteiro e produz a maioria das vagens ao longo dos ramos laterais, ou seja, mais dispersos do que a cultivar Altika, que é semi-rasteira.

O rendimento da cultivar indígena foi inferior à cultivar comercial, demonstrando a eficiência do melhoramento para produtividade, isto é, a cultivar Altika é uma cultivar selecionada e cultivada comercialmente nos E.U.A. Após três anos de armazenamento, a germinação das sementes no campo foi superior a $80 \%$ para Altika e ao redor de $40 \%$ para Makap. Observou-se também, que a cultivar Makap possui considerável resistência em reação à doença Cercosporiose e que as cultivares mostraram a viabilidade para produção comercial de amendoim no meio amazônico.

Com base nestes resultados, foi iniciado um programa de melhoramento genético, procurando-se incorporar os caracteres de produtividade e porcentagem de germinação da cultivar Altika com a resistência à Cercocporiose da cultivar Altika com a resistência a Cercosporiose da cultivar Makap em um único material adaptado à região. Há necessidade de serem avaliadas a reação da cultivar Makap quanto as demais doenças comuns na Amazônia, tais como murcha de Sclerotium e Rhizocto. niose e também observar a época de semeadura adequada, tipo de solos a ser semeada, bem como a qualidade de grãos (teor de óleo). 


\section{SUMMARY}

Two cultivars of peanuts (Arachis hipogaea L.). one indian cultivar (Makap) and one american (Altika), were tested for adaptation, development and pest resistance in Amazon region.

The two cultivars showed good adaptation - Altika cultivar demonstrated good development, grain yield and vigorous seed germination while Makap cultivar demonstrated resistance to Cercospora.

\section{REFERENCIAS BIBLIOGRAFICAS}

\section{CACEX}

1982 - Informação Semanal: Amendoim. Rio de Janeiro, Banco do Brasil S.A. CACEX (17).
GODOY PASSOS, S.M.; CONECHIO FILHO, V \& JOSÉ, A.

1973 - Principais culturas. 2. Ed. Campinas, Inst. Camp. Ens. Agr. p. 98-127.

GREGORY, W.C.; SMITH, B.W; YARBROUGH, J.A.

1951 - Morphology, genetics and breding. In: The unpredictable legume. Published by The Nat. Fert. Ass. Washington, D.C. p. 28-88.

KRAPOVICKAS, A. \& RIGONI, V.A.

1950 - La nomenclatura de las sub espécies y variedades Arachis hipogaea L. Rev. Inv. Agr. Buenos Ayres, 14: 197-228.

(Aceito para publicação em $12 / 11 / 82$ ) 